\title{
A tribological studies of graphite solid lubrication effect on UHMW polyethylene in silicone oil lubricated conditions
}

\author{
Piotr Jabłoński* , Adam Patalas, Piotr Czajka \\ Poznan University of Technology, Institute of Mechanical Technology, Piotrowo 3, 60-965 Poznan, \\ Poland
}

\begin{abstract}
Recent advances in surface engineering and solid lubrication technologies offer unique possibilities for better controlling friction and wear under boundary or marginally lubricated rolling, sliding or rotating contact conditions. The aim of the study was to evaluate influence of graphite solid lubrication addition on silicone oil tribological performance. Studies of graphite solid lubrication effect was carried out with using tribological testing station UMT-2 Bruker. Tests were performed against UHMW polyethylene samples and under various conditions, differing in relative speed and the load of interacting frictional pair.
\end{abstract}

\section{Introduction}

Knowledge about the material characteristics of moving parts is especially important for mechanical engineering, therefore conducting tribological studies is substantial in determination of the usefulness of frictional pairs in different applications. During this studies a variety of engineering materials properties like coefficient of friction, wear resistance and their behavior under lubrication condition might be verified.

It has been documented, that popularity of solid lubrication use in a field of wear resistance is increasing this day. Using of solid lubricant materials is an effective way to simplify design and prolong service life of the operating systems under harsh conditions [1$3]$. The fields in which application of solid lubrication is more preferable than oil or grease lubrication are especially aerospace or food industry and also conditions in which mechanical parts works under high temperatures and pressure [4].

Example of solid lubrication material is ultra-high weight polyethylene (UHMWPE), which mechanical properties such as low coefficient of friction, high wear and chemical resistance in corrosive environment, high impact strength combined with low temperature of embrittlement ensure its stability and the potential for broad applications in various operating conditions at fields of engineering [5]. This material might be used in slide bearings, belt pulleys, tension belt rollers and protective coatings of mining silos interior surfaces and hoppers [6-7].

\footnotetext{
*Corresponding author: piotr.le.jablonski@,doctorate.put.poznan.pl
} 
It has been observed that combining multiple solid lubricants is a successful way in reduction of friction between moving parts [1,9], therefore the aim of conducted research was to evaluate possible use of graphite as an addition to silicon oil in lubrication of friction pairs made of UHMWPE and steel.

\section{Materials and Methods}

The research presented in following paper were conducted with use of tribological testing station Tribotester Brucker UMT-2 in the laboratory at the Faculty of Mechanical Engineering and Management at the Institute of Mechanical Technology of Poznan University of Technology. This station might be used for tribological testing of ferrous, nonferrous metals, plastics, ceramics, composites and various types of coatings, under "dry" and fluid or solid lubrication conditions. The tribological testing station can be programmed for motion in several axes. The ability to control of the trajectory of the sample and the countersample allow to use different methods of evaluation of wear, which are used for evaluation of engineering materials characteristics.

The research on tribological properties of UHMWPE in different lubricating conditions was performed with counter-sample made of martensitic stainless steel X105CrMo17. The trade name of used UHMWPE is TIVAR ${ }^{\circ}$ manufactured by Quadrant EPP. According to Quadrant EPP catalog, used UHMWPE molecular weight is $5 * 10^{6} \mathrm{~g} / \mathrm{mol}$. The samples of UHMWPE were prepared in form of plate $25 \mathrm{~mm}$ in length and $5 \mathrm{~mm}$ in thickness. Diamater of the counter-sample was $6.35 \mathrm{~mm}$.
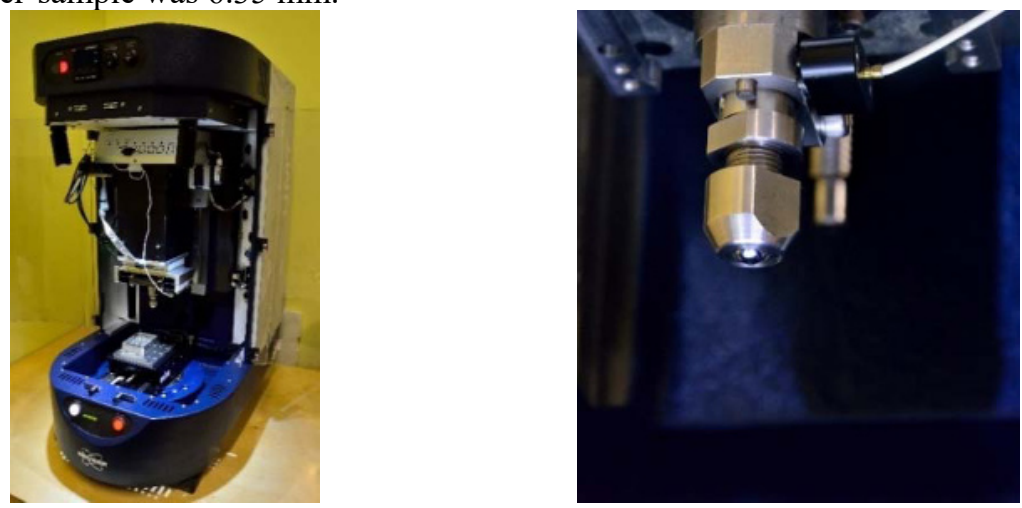

Fig. 1. a) Tribotester Brucker UMT-2 and b) counter-sample of martensitic stainless steel X105CrMo17.

The tribological studies were performed with use of a pin-on-flat method. The kinematic diagram of this method and parameters of the test are show in Figure 2.

The counter-sample performed a reciprocating motion on the fixed sample with an amplitude $\mathrm{L}=20 \mathrm{~mm}$ and a linear velocity $\mathrm{v}=10 \mathrm{~mm} / \mathrm{s}$. While the tests were performed, the counter-sample was set to apply the constant axial force $\mathrm{F}=20 \mathrm{~N}$. 


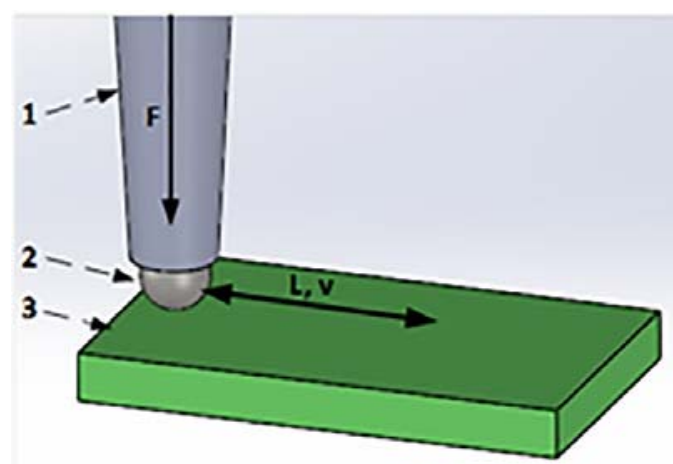

Fig. 2. Kinematic diagram of pin-on-flat method. 1 - griper of counter-sample, 2 - counter-sample, 3 - the sample of UHMWPE.

Using the equations (1) and (2) of the classic Hertzian contact stress theory value of contact pressure between the ball and polymer plate was calculated. In this equations $(a)$ stands as radios of the contact area, $(v)$ is Poisson's ratio, $(E)$ is Young modulus and $\left(R_{l}\right)$ is ball radius (in this case flat radios $\left(\mathrm{R}_{2}\right)$ is understood as a sphere with an infinitely large radius) [8-9].

$$
\begin{gathered}
a=\sqrt[3]{\frac{3 \cdot F \cdot\left(\frac{1-v_{1}^{2}}{E_{1}}+\frac{1-v_{2}^{2}}{E_{2}}\right)}{4 \cdot\left(\frac{1}{R_{1}}+\frac{1}{R_{2}}\right)}}[\mathrm{mm}] \\
p_{\max }=\frac{3 \cdot F}{2 \cdot \pi \cdot a^{2}}[M P a]
\end{gathered}
$$

Parameters which were used to calculations together with obtained results are presented in Table. 1.

Table 1. Parameters and obtained results of Hertzian contact pressure calculations.

\begin{tabular}{|c|c|c|}
\hline & $\begin{array}{c}\text { Steel X105CrMo17 } \\
\text { ball-indenter }\end{array}$ & UHMWPE plate \\
\hline $\mathbf{F}[\mathbf{N}]$ & 6,35 & - \\
\hline $\mathbf{R}[\mathbf{m m}]$ & $2 \cdot 10^{5}$ & 763 \\
\hline $\mathbf{E}[\mathbf{M P a}]$ & 0,283 & 0,317 \\
\hline $\mathbf{v}$ & \multicolumn{3}{|c|}{ Results } \\
\hline & \multicolumn{3}{|c|}{0,48} \\
\hline $\mathbf{a}[\mathbf{m m}]$ & \multicolumn{3}{|c|}{40,92} \\
\hline $\mathbf{p}_{\max }[\mathbf{M P a}]$ & \multicolumn{3}{|c|}{} \\
\hline
\end{tabular}

The maximum allowable contact stresses of UHMWPE is estimated to be equal $15-20$ MPa and according to DIN 53456 hardness of UHMWPE is equal to $35 \mathrm{MPa}$, therefore 
plastic deformation in the contact area between ball indenter and plate was expected. However, it must be remembered that due to high nonlinearity of UHMWPE calculated value of Hertzian contact pressure stress might be different in real [10-11].

The studies consisted of four tribological tests with different conditions of lubrication: dry, silicone oil lubrication and silicone oils suspension with $0.5 \%$ or $1 \%$ graphite addition. Silicone oils have excellent fluid properties and are commonly used as lubricants in systems designed to run under hydrodynamic and elastohydrodynamic conditions where bearings are made with non-ferrous materials. These oils have probably the best viscosity-temperature characteristics of any synthetic oils, with very low volatility and excellent oxidative and thermal stability. Their main disadvantage is the inability to miscible with petroleum oils [8, 12].

Graphite next to molybdenum disulfide is the predominant type of material which can be used as solid lubrication agents or dry lubricants. Graphite is known to be composed of a series of stacked parallel layers. Bonding forces within these layers between carbon atoms are significantly stronger than interatomic bonding forces between the layers. Thus, graphite's physical properties are characterized with layer like anisotropy. This kind of structure is called lamellar structure [4]. This structure is very favorable in sliding motion because the lamellae orient parallel to the surface in the direction of motion and slide easily over each other, resulting in low friction and preventing contact between sliding components even under high loads [12-14].

This study used synthetic graphite from Sigma-Aldrich and universal silicone oil, which was laboratory tested and calibrated to ensure the highest possible consistency and viscosity to $1000 \mathrm{MPa} \cdot \mathrm{s}$.

\section{Results}

During tribological test axial force, frictional force and coefficient of friction was recorded in both the time and cycles function. In Figure 3 are shown the curves of coefficient of frictions change in time for various lubrication conditions.

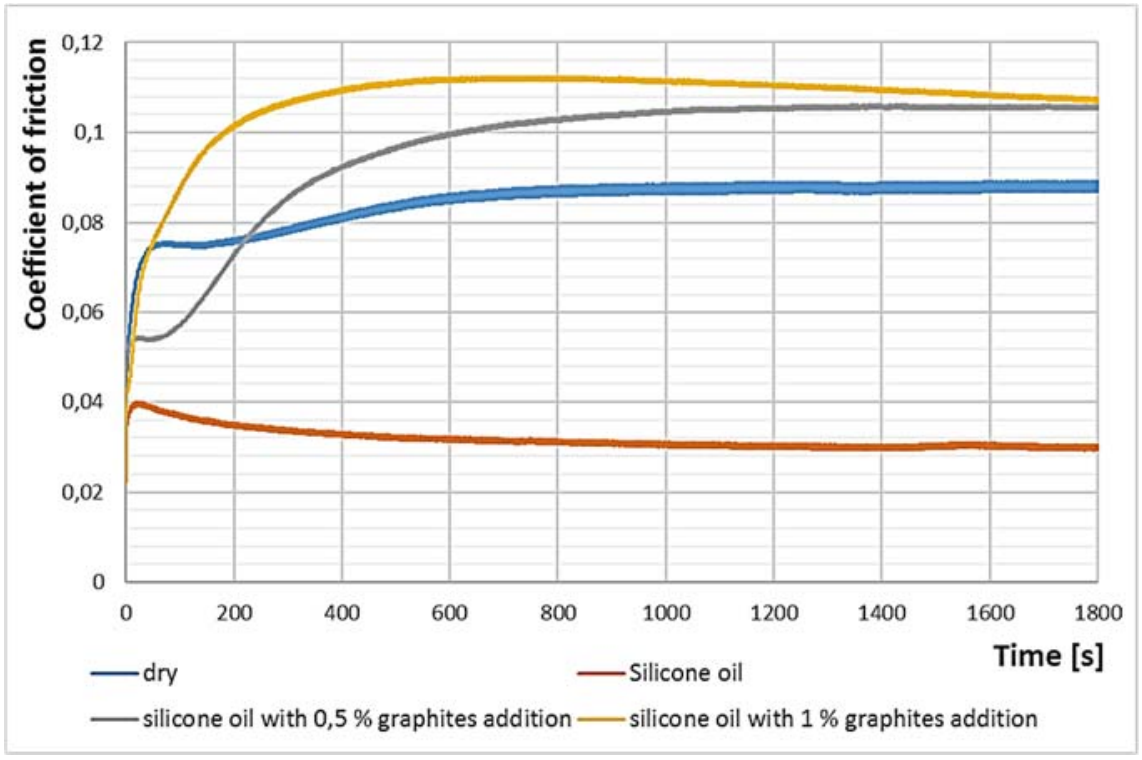

Fig. 3. Changes in the coefficient of kinetic friction for different lubricating agents.

In Table 2 the obtained results of tribological test for different lubricants are presented. 
Table 2. The results of tribological tests for various lubricants.

\begin{tabular}{|c|c|c|c|c|}
\hline & Dry & $\begin{array}{c}\text { Silicone } \\
\text { oil }\end{array}$ & $\begin{array}{c}\text { Silicone oil with } \\
\mathbf{0 , 5 \%} \text { graphite } \\
\text { addition }\end{array}$ & $\begin{array}{c}\text { Silicone oil with } \\
\text { 1\% graphite } \\
\text { addition }\end{array}$ \\
\hline $\begin{array}{c}\text { The mean coefficient of friction } \\
\text { after stabilization time }\end{array}$ & 0,087 & 0,030 & 0,106 & 0,107 \\
\hline $\begin{array}{c}\text { The maximal coefficient of } \\
\text { friction }\end{array}$ & 0,089 & 0,040 & 0,106 & 0,112 \\
\hline The time of stabilization & $800 \mathrm{~s}$ & $900 \mathrm{~s}$ & $1100 \mathrm{~s}$ & - \\
\hline
\end{tabular}

The kinetic coefficient of friction measurements for dry samples and lubricated by silicone oil with/without $0.5 \%$ and $1 \%$ graphite addition, has been shown to increase the coefficient of kinetic friction in early time of test. Only in case of lubrication under pure silicone oil conditions are not shown pronounced changes.

During tribological test stabilization of measured value of coefficient of friction was observed. Time of stabilization is evident on curves in Figure 3 and are appointed. A stabilization of measured value of coefficient of friction indicates that used parameters number of cycles, counter-sample, velocity, and its amplitude - were chose correctly.

In Table 2 the mean values of coefficient of friction that achieved after stabilization time are compared. There is noticeable, that the terminal coefficient of friction for silicone oil condition are nearly three times lower in comparison with dry samples. It is surprising that in tribological tests with silicone oil with graphite addition the highest value of the kinetic friction coefficient are reached.

\section{Conclusions and Planned Further Research}

The aim of this study was to perform tribological research for frictional pair made of UHMWPE and stainless steel $\mathrm{X} 105 \mathrm{CrMo} 17$ under various conditions of lubrication. Conducted research allowed to obtain data about values of the coefficient of friction under: dry, silicon oil, and silicon oil with addition of graphite lubrication. Base on the research results (see table 1 and chart presented in Figure 3 the following conclusions were set out:

- Use of the silicon oil as a lubricant for the tested friction pair resulted in significant decrease of coefficient of friction value from 0,087 to 0,03 - approximately 3 times drop in value. This was caused by formation of oil film that separated surfaces of sample UHWMPE and steel counter-sample.

- Addition of graphite to silicon oil had negative synergy influence on lubrication of tested friction pair. As it is presented in Figure 1 addition of $0.5 \%$ and $1 \%$ graphite significantly affected measured value of the coefficient of friction which in both cases was higher than the coefficient of friction on dry surfaces. The probable cause was a graphite indentation into UHMW Polyethylene surface that resulted in in change of friction pair from UHMWPE-steel into graphite-steel.

- Another possible reason of coefficient of friction increase, was breaking of oil film caused by change in lubrication condition from fluid into boundary lubrication, as the result of graphite particles adherence to surface of the steel counter-sample and graphite indentation into UHMWPE. In this case friction pair was changed from UHMWPE-steel into graphite-graphite.

- Obtained data indicates that in this case addition of graphite to silicon oil is not recommended.

- In future research possible use of lubrication by silicon oil with addition of such solid lubricant as: expanded graphite with a highly developed specific surface area, 
hBN or $\mathrm{MoS}_{2}$ will be tested in application for friction pairs made of different engineering materials i.e. steel-steel, steel-ceramics.

\section{References}

1. J. Zhena, J. Chenga, S. Zhua, J. Haoa, Z. Qiaoa, J. Yanga, Trib. Inter., 110, p. 52-56, (2017)

2. R.W. Maruda, E.E. Feldshtein, S. Legutko, et al., J. of Fri. and Wear, 36, p. 548-553 (2015)

3. K. Adamczuk, S. Legutko, G. M. Krolczyk, R. W. Maruda, App. Mech. and Mat., 809810, p. 1055-1060, (2015)

4. K. Miyoshi, Solid Lubrication Fundamentals and Applications, CRC Press, (2001)

5. S. V. Panin, L. A. Kornienko, V. O. Alexenko, L. R. Ivanova, Key Eng. Mat., 712, p. 155-160, (2016)

6. P. Siwak, A. Patalas, P. Jabłoński, K. Peta, Trib., p. 139 - 148, (2016)

7. Braskem - Brochure of produced Ultra High Molecular Weight Polyethylene https://www.braskem.com.br/Portal/Principal/arquivos/HRP_15-

016_v02_UTEC_Brochure_iPad.pdfHigh-temperature tribological behavior of a nickel alloy matrix solid lubricating composite under vacuum, (access 20.02.2017)

8. G. W. Stachowiak, A. W. Batchelor, Engineering Tribology, Butterworth-Heinemann, (2005)

9. S. D. Mesarovic, N. A. Fleck, The Royal Society, 455, pp. 2107-2128 (1999)

10. Z.M. Jin, D. Dowson, J. Fisher, Med. Eng. \& Phys., 16, p. 398-405, (1994)

11. GG Tech - http://www.ggtech.com.pl/12-polietylen-pe, (access 27.03.2017)

12. T. Hisakado, T. Tsukizoe, H. Yoshikawa, J. of Lub. Tech., 105, 2, (1983)

13. B. Chen, Q. Bi, Y. Xia, J. Hao, Trib. Inter., 41, 12, p. 1145-1152 (2008)

14. J. C. Spear, B. W. Ewers, J. D. Batteas, Nano Today, 10, 3, p. 40-43 (2015) 